\title{
Factors driving employee participation in corporate BYOD programs: A cross-national comparison from the perspective of future employees
}

\author{
Xuequn Wang \\ Murdoch University \\ xuequnwang1600@gmail.com
}

Andy Weeger
Neu-Ulm University of Applied Sciences
Heiko Gewald
Neu-Ulm University of Applied Sciences

\section{Abstract}

As individuals all around the world increasingly use mobile devices in their daily life, their desire to use the same devices in the workplace continuously grows. In response, organizations are more and more allowing their employees to use their own devices for both business and private purposes and offer so called 'Bring-your-own-Device' (BYOD) programs. For organizations with global operations there is a need to examine the drivers of BYOD demand across different national cultures to assess how to develop a successful BYOD program. Based on recent literature on BYOD, we examine how different factors contribute to employees' behavioural intention to participate in a BYOD program across different national cultures. The model was examined by surveying students from China, Germany and U.S. in their final term. The results show significant cross-cultural differences, particularly regarding the 'Perceived Threats'. Overall this study offers novel insights for cross cultural BYOD implementations.

Keywords: IT consumerization, cultural differences, bring-your-own-device (BYOD), behavioural intention, UTAUT

\section{Introduction}

The widespread availability of mobile devices like smart phones and tablet computers in combination with increased wireless coverage and the accompanying decrease in costs for data communication has resulted in accelerated diffusion of mobile services, specifically in developed economies (Min 2010). In 2013, worldwide sales of smart phones surpassed sales of basic feature mobiles (Lomas 2014) and nowadays the latter are hardly sold anymore. Individuals all over the world accustomed to the convenience of using their advanced mobile devices whenever and wherever they want (Johnson and Joshi 2012). This trend induced a major shift in the deployment and management of information technology (IT). The driving force for the diffusion of innovative end user technologies shifted from the IT-department to the consumer (Beimborn and Palizta 2013). Contemporary employees are more comfortable with the functionalities of their consumer devices than with the devices provided by corporate IT (Gajar et al. 2013, Steelman et al. 2016). There are also more knowledgeable about available options than generations before.

In line with these developments, employers nowadays regard flexibility and mobility as essential attitudes (Harris et al. 2012), and employees are increasingly expected to complete their business tasks quickly, efficiently and from anywhere (Johnson and Joshi 2012). In order to meet these requirements, employees increasingly expect to be able to fulfil their tasks in the manner they chose and to use the devices they are familiar with, i.e. their own devices.

The trend of using consumer IT resources (devices, systems and services) in both private and business contexts is referred to as the 'consumerization of IT' (Harris and Junglas 2011; Holtsnider and Jaffe 2012; Ingalsbe et al. 2011). 'Bring-Your-Own-Device' (BYOD) refers to 
employers allowing and sometimes even encouraging their employees to use privately owned mobile devices to complete business tasks (Lebek et al. 2013). BYOD initiatives are increasingly prevalent among enterprises worldwide (Johnson and Joshi 2012, Steelman et al. 2016).

Although BYOD is getting more popular in practice, Information Systems (IS) research has not yet reached full understanding of this phenomenon. In particular the factors influencing IT consumerization were identified as area in need of further research (Dernbecher et al. 2013). BYOD is a global issue following the trend of globalization. Companies of all sizes operate in several countries, having to cater for a cross-cultural workforce. These corporations need to take the differences and characteristics of national cultures and values of their workforce into account. Previous IS literature has shown that culture is critical to understand IS phenomena (Leidner and Kayworth 2006) such as technology adoption (Li et al. 2010; Park et al. 2004). However, previous IS research has under-investigated country-based differences of the relationship between constructs ( $\mathrm{Li}$ et al. 2010). Thus, there is a need to examine the factors driving employees across different countries to participate in BYOD programs.

BYOD is a phenomenon that swamped from private life into the business context (Steelman et al., 2016). The generation currently entering the workplace (so called "digital natives" (Prensky 2001)), grew up being "always on". As such they cannot imagine a true offline world anymore (Colbert et al., 2016). These young people often see BYOD as a necessity of daily life (Fenn et al., 2011) and demand it from their future employers. As attracting highly skilled talent, especially in IT, proves to be ever more difficult for companies these days, the pressure arising to provide BYOD programs increases.

Connecting the aforementioned arguments, the research question of this study is: What are the factors driving future employees across different cultural backgrounds to participate in corporate BYOD programs?

Our study examines how different factors influence individuals' intention to participate in BYOD programs based on data from three economically strong countries (China, Germany and U.S.) which host several multinational corporations. Cross-cultural IT use is still underinvestigated, and previous literature particularly has not fully examined if research models developed in one country can be generalized to other countries (Zhao et al. 2007). Recently, Weeger et al. (2015) proposed and tested a model examining how various factors influence individuals' intention to participate in BYOD programs. The research presented here extends the aforementioned study to examine their model across different countries. Thus, we contribute to global IT research and provide insights for practitioners how to deploy BYOD programs across different countries. Especially, companies may face challenges to operate in different countries of Pacific Asia due to varying cultures and workplace habits. Therefore, understanding the effect of cultures can help those companies to more successful deploy their BYOD programs in different countries (French et al. 2014).

The paper is structured as follows: In the following section, previous literature on IT consumerization and BYOD, technology related service adoption and cross-cultural IS research is discussed. Based on this literature review, the research hypotheses and research model are developed. Subsequently, research method and data analysis follow. Finally, the implications for theory and practice are discussed.

\section{Literature Review}

\subsection{IT Consumerization and Bring-Your-Own-Device (BYOD)}

IT consumerization is frequently conceptualized as the dual use of consumer devices, applications and services for private and business purpose (Harris and Junglas 2011; Holtsnider and Jaffe 2012; Ingalsbe et al. 2011), hence, defined as a scenario in which employees "invest their own resources to buy, learn, and use consumer technology at their workplace" (Niehaves et al. 2012, p. 2). Focusing on mobile hardware devices, BYOD is defined as the act of connecting a personally owned device to the corporate network and using it for business purposes (see e.g. Harris et al. 2013). 
IT consumerization and BYOD are consequences of a reversed technology adoption lifecycle (Baskerville 2011; Jaramillo et al. 2013; Weiß and Leimeister 2012). In the past, innovative IT first emerged in the professional context (e.g. the personal computer) and then spread into consumer markets. Today, the diffusion of new IT can also be triggered by employees and then find its way into business (e.g. the iPhone). Innovative IT first enters the consumer market, employees adopt it for private purposes and get familiar with the technology and its characteristics (e.g. ease of use, flexibility). Consequently they are expecting similar qualities from corporate IT and/or are starting to use their private devices for business purposes without consent from corporate IT. Subsequently, boundaries between consumer and business technologies begin to blur (Colbert et al., 2016).

This trend can be observed with the diffusion of smartphones. The advantages of mobile devices targeted at the consumer sector have changed employee's expectations towards corporate IT (Weiß and Leimeister 2012). The devices provided by the IT department are specifically developed for corporate use (e.g. the Blackberry which is still very popular in corporate settings around the world) but frequently not match up to consumer devices in terms of usability and user experience (Murdoch et al. 2010; Harris et al. 2011). Furthermore, it was demonstrated that conducting work tasks by using privately-owned devices provides benefits such as greater autonomy and flexibility (Harris and Junglas 2011; Murdoch et al. 2010). Some scholars even expect IT consumerization to contribute positively to work performance by increasing satisfaction, flexibility and mobility (Niehaves et al. 2013; Romer 2014). On organizational level, significant cost reductions for organizations are expected (Ingalsbe et al. 2011; Holtsnider et al. 2012).

On the other hand, the phenomenon is also seen critically and several disadvantages for employees and organizations are pointed out. On the employee level, it is supposed that productivity gains go with increased individual workload and blurred boundaries between business and private lives (Ingalsbe et al. 2011; Niehaves et al. 2012). For organisations, security issues, increasing complexity, loss of control and performance issues are pointed out as negative effects (Colbert et al., 2016, Niehaves et al., 2012; Tokuyoshi 2013) and it is expected that IT management in organizations is challenged for the foreseeable future (Weiß and Leimeister 2012).

In an effort to avoid end users to connect their devices uncontrolled to the corporate network and to safeguard data security, technology standardization and compatibility (Györy et al. 2012), many organizations establish official BYOD programs (Harris et al., 2012). These initiatives enable employees to choose and use devices selected on their own. Usually these programs comprise definitions of the technical requirements privately owned devices have to meet and policies with respect to BYOD usage, security, and liability which employees have to accept (Crossler et al. 2014; Harris 2012; Vogel et al. 2010). For example, employees typically must permit their employer to remove all data from BYOD devices ("wipe out") if the item is lost or the employee resigns (Harris et al. 2012).

\subsection{BYOD Adoption and UTAUT}

BYOD initiatives are service offerings by organizations to their employees. Recently, literature has begun to examine various aspects of BYOD usage. Some studies focus on employees' compliance to information security policies when using BYOD (Alaskar and Shen, 2016; Crossler et al., 2014; Hovav and Putri, 2016). Crossler et al. (2014) found that self-efficacy, response efficacy, threat severity and cost to comply can influence individuals' motivation to comply with a BYOD policy. Other studies examines BYOD intention and usage. Wang and Nemati (2016) draw Complex Adaptive Systems as a theoretical lens to explore a holistic understanding of BYOD usage.

On the other hand, few studies have examined BYOD across different cultures. Prior literature shows that Unified Theory of Acceptance and Use of Technology (UTAUT) is well suited to explain the adoption of technology related services (Amberg et al. 2004; Chen et al. 2007; Hung and Chang 2005; Mallat et al. 2008). The main argument of UTAUT is that there are three variables (i.e., performance expectancy, effort expectancy and social influence) 
impacting people's behavioural intention, and two variables (i.e., facilitating conditions and behavioural intention) directly influencing technology use (Venkatesh et al. 2003). Besides, gender, age, experience and voluntariness moderate the relationships between these variables and intention and / or behaviour. Recently, Weeger et al. (2015) propose a modified UTAUT to examine people' intention to adopt BYOD services. The authors conducted two modifications: First, facilitating conditions are excluded since the model does not examine BYOD usage behaviour. Second, perceived threats are added to cover the negative aspect of BYOD adoption. In this study, we extend the previous work of Weeger et al. (2015) by examining how the effects of various factors on BYOD adoption intention differ across various cultures, thus contributing previous literature by providing useful insights regarding how to deploy BYOD programs globally.

\subsection{Cross-Cultural IS Research}

BYOD is a challenging phenomenon for IT executives worldwide. Although BYOD is present in virtually all developed economies, anecdotal evidence from multi-national companies shows that the motivational factors are quite different. This is supported by prior research which shows that characteristics of national culture strongly impact an individual's adoption behaviour (Srite and Karahanna, 2006). National culture refers to "the collective programming of the mind that distinguishes the members of one group or category of people from another" (Hofstede 2001, p. 9). Hofstede (2001) proposes five dimensions of national cultures: power distance, uncertainty avoidance, individualism / collectivism, masculinity / femininity, and long / short term orientation.

Hofstede's culture dimensions have been widely applied in various contexts. Previous crosscountry IS studies have examined the role of national cultures in influencing customer satisfaction with online stores (Lee et al. 2009), behavioural intention towards usage of instant messaging services ( $\mathrm{Li}$ et al., 2010), purchasing behaviour in e-commerce (Park et al. 2004) and security awareness (Schmidt et al. 2008) to name just a few.

\section{Research Model}

In this study, we examine an individual's decision to participate in a corporate BYOD program across different cultures drawn on the model from Weeger et al. (2015). The research model and its constituting constructs, proposed relationships and hypotheses are depicted in Figure 1 .

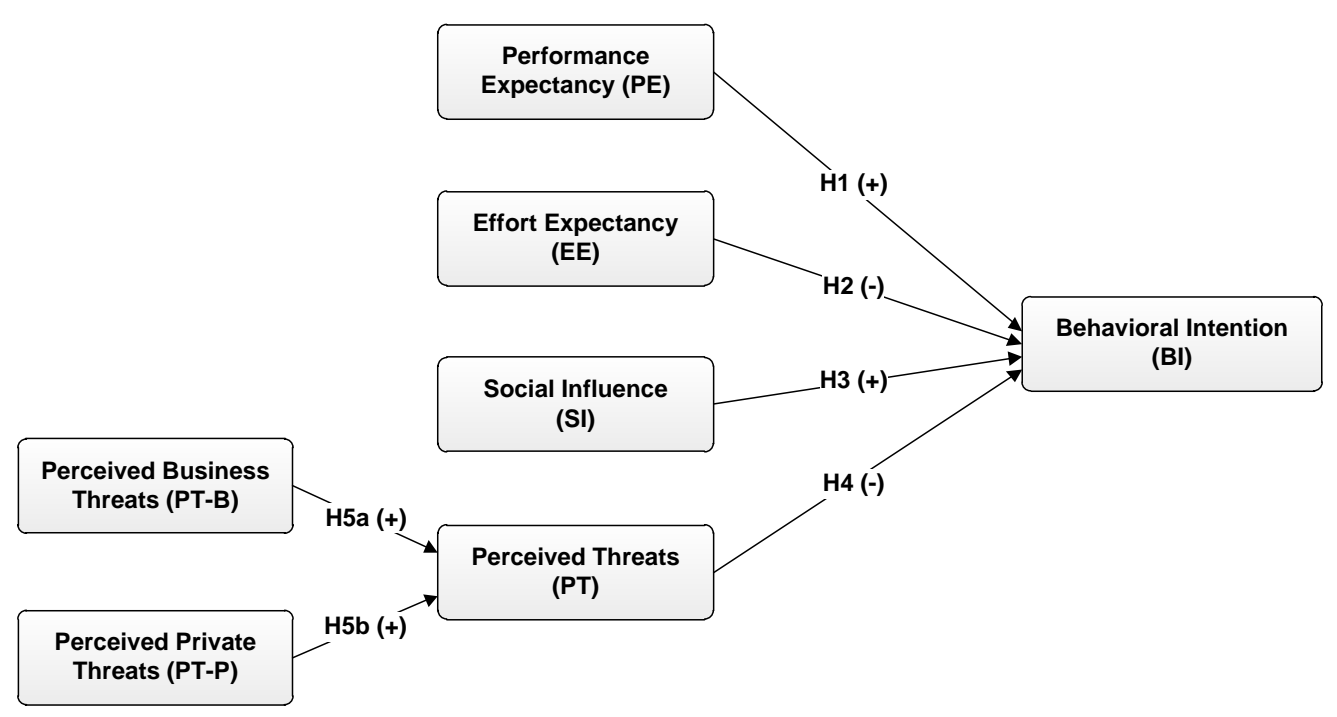

Figure 1: Research model 


\subsection{Cultural Values}

In response to McCoy et al.'s (2005, p. 211) call that as "globalization of businesses and systems continues to increase, our understanding about the adoption and use of IT needs to apply to other cultures", we aim to understand to what extend culture impacts BYOD decision making. Particularly, it is of interest to understand if and how the factors driving individuals to participate in a BYOD program vary across different cultural backgrounds.

Among the five dimensions of national cultures proposed by Hofstede, individualism /collectivism and uncertainty avoidance are particular relevant to understand the adoption of BYOD programs. Uncertainty avoidance refers to the extent to which individuals feel threatened by ambiguous situations (Hofstede 2001). People with high uncertainty avoidance try to avoid all forms of uncertainty by establishing formal rules and rejecting deviant ideas and behaviours. Since outcomes of adopting BYOD services can be negative in certain contexts and are indeed uncertain, people with a high level of uncertainty avoidance may perceive the threats associated with BYOD services (i.e., perceived threats) more severely and choose not to adopt these services.

Individualism / collectivism describes the relationship between individuals and a group, and refers to if individuals' interests are prioritized over those of a group (Hofstede 2001). One important distinction between individualism and collectivism is individuals' personality orientation (idiocentric vs. allocentric) (Triandis 1989). People from individualistic cultures are more idiocentric, feel comfortable to "do their own thing" and deemphasize the interest of the group to which they belong (Triandis et al. 1988). Those people are often emotionally separated from groups and emphasize personal achievement and productivity. On the other hand, people from collectivist cultures are more allocentric, share the interests of the group, and function as interdependent members. Therefore, individualism / collectivism probably influence the effects of performance expectancy, effort expectancy and social influence.

\subsection{Performance Expectancy}

In line with UTAUT's definition, performance expectancy is defined as the degree to which an individual believes that participating in a BYOD program will help him or her to attain gains in job performance (Venkatesh et al. 2003). Previous literature has identified several advantages of participating in a BYOD program such as higher flexibility and mobility (e.g. Niehaves et al. 2012). In addition, Niehaves et al. (2013) conclude that BYOD is also able to contribute to work performance as employees realize productivity gains when they are able to select IT tools on their own.

From a cultural perspective, the effect of performance expectancy is probably more important for people from individualistic cultures (e.g., U.S.) than for those from collectivistic cultures (e.g., China). People from individualistic cultures emphasize personal achievement and productivity. Therefore, when considering participation in a corporate BYOD program, their behavioural intentions are more likely to be driven the perceptions of whether the BYOD program can provide pragmatic gains, such as improved job performance. Subsequently we propose that:

H1: There is a positive association between performance expectancy and intention to participate in a BYOD program, and this association is strongest in the U.S. and weakest in China.

\subsection{Effort Expectancy}

Individuals using their personal devices on the job are most likely familiar with the functionalities of their devices. Nevertheless, some effort arises when participating in a corporate BYOD program (set up the device accordingly, reading the applicable corporate policies, complying with these policies, etc.). Expectations about this effort probably cushions behavioural intention. In analogy to Thompson et al. (1991) effort expectancy is defined as the degree to which participating in a BYOD program is perceived as relatively difficult. 
Individualism / collectivism is also expected to affect the relationship between effort expectancy and behavioural intention. People from individualistic culture (e.g., U.S.) put more emphasize on task performance and productivity. Therefore, they tend to focus more on important goals (Srite and Karahanna 2006) and try to achieve those goals more efficiently than those from collectivistic cultures (Dagwell et al. 1983). Effort expectancy is directly related to efficiency: when the expected effort of the BYOD program is high, people need to spend more effort to finish their tasks. In such a context, people from individualistic natures are more likely to feel less efficient, decreasing their intention to participate in a BYOD program. Therefore, we hypothesize that:

H2: There is a negative association between effort expectancy and intention to participate in a BYOD program, and this association is strongest in the U.S. and weakest in China.

\subsection{Social Influence}

Social influence is defined as the degree to which an individual perceives that important others think he or she should perform certain behaviour, in this case enrol in a corporate BYOD program (Moore and Benbasat, 1991). Although prior findings on the effect of social influence on behavioural intention are somehow mixed (e.g. Venkatesh et al., 2003; Arruda-Filho et al., 2010; López-Nicolás et al., 2008), having the opportunity to purchase fashionable devices such as an iPhone or iPad that meet both private and business needs has the potential to enhance an individual's image perceptions. Thus, it is hypothesized that expected social gains will impact an individual's behavioural intention.

From a collectivistic culture (e.g., China) people probably function as interdependent members and share the interests of the group. Therefore, people from collective cultures value the image and prestige within the group more as they emotionally attached to the group. In other words, in a strong collective culture, people tend to work collectively and respect others ideas and opinions; thus, they are more likely to comply with the opinions of important others (Srite and Karahanna 2006). As a consequence, if participating in a BYOD program is valued by colleagues and can positively increase individuals' image within the organization, people from collectivistic cultures are more likely to participate in a BYOD program. Therefore, we propose:

H3: There is a positive association between social influence and intention to participate in a BYOD program, and this association is strongest in China and weakest in the U.S.

\subsection{Perceived Threats}

Perceived threats are defined as the extent to which individuals apprehend that BYOD usage may worsen the status quo (Weeger et al. 2015). Perceived threats include two dimensions: business related threats and threats related to private life (Niehaves et al. 2012). Typical business related threats include being responsible for a disclosure or loss of business data if the device gets stolen, malwares disrupting the corporate IT infrastructure, or violating company policies (Niehaves et al. 2012). Commonly cited threats to private life are that companies typically reserve the right to remove both private and business-related data from a lost device (Harris et al. 2012), that the employers obtain private data from the device, and that the boundaries between private and business life are blurred.

Uncertainty avoidance can be useful to understand how the effects of perceived threats differ across different cultures. According to Hofstede (2001), uncertainty avoidance represents how people feel threatened by unknown situations. Therefore, the level of uncertainty avoidance shows how people are tolerant to various threats and risks. Previous literature has found that people from high uncertainty avoidance cultures are more likely to show a higher level of risk aversion and a lower level of satisfaction in the context of e-commerce (Lee et al. 2009). In the context of BYOD, people from a low level of uncertainty avoidance culture (e.g., China) are relatively comfortable with ambiguity and threats, so threats may not have a strong effect on intent to participate in a BYOD program. On the other hand, those from a high level of 
uncertainty avoidance culture (e.g., Germany) may try to avoid threats, and the effect of potential threats is assumed to have a stronger effect. Therefore, it is hypothesized that:

H4: There is a negative association between perceived threats and intention to participate in a BYOD program, and this association is strongest in Germany and weakest in China.

Weeger et al. (2015) model perceived threats as a second-order multi-faceted construct encompassing perceived business threats and perceived private threats. Perceived business threats are defined as "the extent to which an individual perceives using personal devices for business purposes as threatening his or her job performance" (p. 4). Perceived private threats are defined as "the extent to which an individual perceives participating in a corporate BOYD program as compromising his or her private life" (p. 3). Both dimensions are expected to contribute to the overall threats perceived by an individual. Subsequently, it is hypothesized that:

H5a: There is a positive association between perceived business threats and perceived threats.

$H_{5} b$ : There is a positive association between perceived private threats and perceived threats.

\section{Research Methodology}

The model was tested using a questionnaire through an online survey among students from Germany, China, and the U.S. Below, the rational for choosing a student sample, instrument development and data collection are discussed below.

\subsection{Sample}

Current students were born into the 'digital age' where technology is ubiquitous and are therefore referred to as 'digital natives' (Prensky, 2001). It is expected that IT consumerization will gain even more momentum in the future driven by these digital natives (Fenn et al., 2011). As today's students are the work-force of tomorrow their relationship to technology will influence the future way of working. Therefore we decided to examine student's intention to participate in a BYOD program.

In order to decide whether to participate in an official BYOD program relevant work experience is necessary. Therefore, the research participants of this study are students in their final year of study who already collected significant work experiences during their studies (such as an internship or a practical semester). Moreover, we focused on students with business, information systems or engineering majors only based on the assumption that these students are tech savvy and have an opinion on BYOD.

Germany, U.S. and China were selected to examine the effect of cultural values on BYOD adoption for two reasons. First, those three countries are among the top 14 mobile market with over 100 million mobile subscriptions (Global mobile statistics 2013). Thus, people from those countries probably often use mobile devices in their daily life and make sense of the research context. Second, those three countries are from different regions and have different scores of Hofstede (2013)'s national cultures, making cross-national comparison appropriate. Specifically, previous literature has often selected China and U.S. as representative of the collectivist and individualistic culture respectively (Hofstede 1991; Li et al. 2010). By selecting Germany as the additional research context, our study can complement previous cross-culture IS literature and provide additional insights of individualism / collectivism culture (Table 1). Besides, Germany is regarded as a high uncertainty avoidance culture, and it is appropriate to compare Germany to China and U.S. on uncertainty avoidance. 


\begin{tabular}{lccccc}
\hline & $\begin{array}{c}\text { Power } \\
\text { distance }\end{array}$ & Individualism & Masculinity & $\begin{array}{c}\text { Uncertainty } \\
\text { avoidance }\end{array}$ & $\begin{array}{c}\text { Long-term } \\
\text { orientation }\end{array}$ \\
\hline Germany & 35 & 67 & 66 & 65 & 31 \\
China & 80 & 20 & 66 & 30 & 118 \\
U.S. & 40 & 91 & 62 & 46 & 29 \\
\hline
\end{tabular}

Table 1: National cultural dimensions (Hofstede 2013)

\subsection{Instrument}

In order to safeguard a similar understanding of BYOD programs among the participants, the applicable BYOD concept was given in the beginning of the questionnaire:

Corporate BYOD programs enable employees to use their private IT devices for business purposes. This study builds upon the BYOD concept 'we sponsor your device' where the employee purchases a/several mobile device(s) (e.g., a smartphone, notebook, tablet), agrees to use the device(s) for business purpose and receives financial compensation from the company. This compensation is usually fixed and valid for a given time frame (e.g., \$4,ooo for four years). The employee can freely decide which devices he or she uses within this time frame. As the company usually does not provide the employee with additional devices for business purpose, he or she is fully responsible for having sufficient IT equipment to fulfil his or her business needs.

Items from Weeger et al. (2015) were used as basis. All items were discussed intensively within the research team to assess whether these items can capture corresponding constructs. Furthermore, a pre-test within the target group was conducted to ensure that the questionnaire is comprehensible and unambiguous. Additional tests were conducted to ensure that indicators of perceived threats are clearly distinguished and that every aspect of the construct has been captured. Table 2 summarizes the latent variables, their types (reflective or formative), and the number of items. Please note that perceived threats are measured as a second-order formative construct by perceived private threats and perceived business threats. The measurement items used in the instrument are presented in Table A.1.

\begin{tabular}{lcc}
\hline \multicolumn{1}{c}{ Construct } & Type & Items \\
\hline Behavioural intention (BI) & Reflective & 3 \\
Performance expectancy (PE) & Reflective & 4 \\
Effort expectancy (EE) & Reflective & 3 \\
Social influence (SI) & Reflective & 4 \\
Perceived threats (PT) & Formative & 8 \\
Perceived private threats (PBT) & Formative & 4 \\
Perceived business threats (PPT) & Formative & 4 \\
\hline
\end{tabular}

Table 2: Construct operationalization

\subsection{Data Collection}

In order to recruit participants, professors of higher education institutions in Germany, the U.S. and China were invited to participate in the study ${ }^{1}$. Data was collected during a period of four weeks in December 2012. Professors in the research group asked undergraduate students in their last terms to participate in the online survey. To ensure that students can assess the effects of BYOD realistically, only students with relevant work experiences (such as an internship or a practical semester) were invited to participate. To reduce nonresponse bias during data collection, the professors regularly reminded their students to participate.

In total, 485 responses were collected and reviewed to identify whether respondents completely finished the survey. Our analysis revealed that 183 lacked at least one value

\footnotetext{
${ }^{1}$ We gratefully acknowledge support for data collection provided by the following scholar: Mahesh S.
} Raisinghani. 
(including demographics), resulting in 302 usable responses for the complete dataset. The demographics of the sample are depicted in Table $3^{2}$.

\begin{tabular}{llllll}
\hline Gender & Male & $54.0 \%$ & Country & U.S. & $38.7 \%$ \\
& Female & $46.0 \%$ & & China & $33.4 \%$ \\
\cline { 1 - 2 } Age & $<18$ years & $0.3 \%$ & & Germany & $27.8 \%$ \\
& $18-21$ years & $42.4 \%$ & & & \\
& $22-25$ years & $28.8 \%$ & & & \\
& $26-29$ years & $13.9 \%$ & & & \\
& $>29$ years & $14.6 \%$ & & & \\
\cline { 1 - 2 } Study Focus & Business & $72.5 \%$ & & & \\
& Engineering & $16.2 \%$ & & & \\
& Interdisciplinary & $11.3 \%$ & & & \\
\hline
\end{tabular}

Table 3: Demographics of the Dataset

\section{Data Overview}

The model was tested using PLS3, a structural equation modelling method for complex predictive models and theory building (Barclay et al. 1995; Chin 1998; Lohmöller 1989). PLS is the preferred analytical technique of this study because of its compatibility with formative measurement (Gefen et al. 2011). Besides, Shapiro-Wilk tests were significant, showing that the measurements were not normally distributed. According to Hair et al. (2014), PLS is more appropriate with non-normally distributed data 4 .

Before evaluating the models, we conducted two common method variance (CMV) tests to examine whether common method bias was a concern (Lindell and Whitney 2001; Podsakoff et al. 2003). First, an explanatory factor analysis of all items extracted four factors explaining $63.42 \%$ of the variance, with no single factor accounting for significant loading (at the $p<0.05$ level) for all items. Second, we used the second-smallest positive correlation among the manifest variables as a conservative estimate for CMV. After adjustment, all significant correlations remained significant. Therefore, CMV is probably not a concern in this data set.

\subsection{Measurement Model Assessment}

The measures of reflective constructs from the German dataset demonstrate good psychometric properties. Convergent validity was confirmed by meeting the following criteria (e.g. Gefen and Straub 2005; Hulland 1999): (A) the loadings of each item were all significant and above the cut-off value of 0.60 (Table 3); (B) the composite reliabilities (CRs) of all constructs were above 0.70 (Table 3); (C) the average variance extracted (AVE) of all constructs was above the threshold value of 0.50 (Table 4). Discriminant validity was established by ensuring that the square root of AVE for each construct exceeded the correlations between that construct and any other construct (Gefen and Straub, 2005) (Table 5).

\footnotetext{
${ }^{2}$ Here we use "country of study" as indicator of culture. We also conducted separate analyses based on "country of origin" and found no significant differences.

3 The software SmartPLS 2.0 (Ringle et al. 2005) was used to estimate the model and the bootstrap resampling method (using 5,000 samples) was used to determine the significance of the paths in the structural model.

4 We also checked skewness and kurtosis and their values are below 1.96. Therefore, the values of skewness and kurtosis are not significant $(\mathrm{p}>.05)$ and our data is not highly non-normal.
} 


\begin{tabular}{cccccc}
\hline Scale Item & Item Mean & Item S. D. & $\begin{array}{c}\text { Item } \\
\text { Loading }\end{array}$ & AVE & CR \\
\hline BI1 & 2.74 & 1.09 & 0.93 & 0.86 & 0.95 \\
BI2 & 2.68 & 1.04 & 0.92 & & \\
BI3 & 2.73 & 1.10 & 0.92 & 0.66 & 085 \\
EE1 & 2.51 & 0.86 & 0.78 & & \\
EE2 & 2.05 & 0.82 & 0.86 & & \\
EE3 & 2.38 & 1.02 & 0.78 & 0.67 & \\
PE1 & 2.94 & 0.97 & 0.88 & & \\
PE2 & 2.55 & 0.92 & 0.73 & & \\
PE3 & 2.98 & 1.11 & 0.85 & & \\
PE4 & 2.96 & 0.99 & 0.82 & & \\
SI1 & 3.45 & 1.07 & 0.91 & & \\
SI2 & 3.38 & 1.10 & 0.92 & & \\
SI3 & 3.43 & 1.25 & 0.88 & & \\
SI4 & 3.57 & 1.03 & 0.84 & & \\
\hline
\end{tabular}

Table 4: Descriptive statistics, item loadings and constructs' AVE and CR (Germany)

\begin{tabular}{ccccc}
\hline Construct & BI & EE & PE & SI \\
\hline BI & $\mathbf{0 . 9 2}$ & & & \\
EE & 0.32 & $\mathbf{0 . 8 1}$ & & \\
PE & 0.70 & 0.31 & $\mathbf{0 . 8 2}$ & \\
SI & 0.21 & -0.22 & 0.16 & $\mathbf{0 . 8 9}$ \\
\hline
\end{tabular}

Table 5: Correlation between constructs and square-root of AVEs (Germany)

For indicators of threat-constructs (PBT and PPT), collinearity needs to be assessed by examining variance inflation factor (VIF) and tolerance value for each indicator. The results show that no indicators from perceived private threats and perceived business threats have a tolerance value below 0.20 or a VIF value above 5 , indicating that collinearity is probably not an issue. Then the weights of each indicator were examined (Table 6). Only the weights of the indicator PBT4 from PBT and the indicator PPT1 from PPT are significant.

\begin{tabular}{ccc}
\hline Construct & PBT & PPT \\
\hline PBT1 & 0.17 & \\
PBT2 & 0.22 & \\
PBT3 & 0.33 & \\
PBT4 & $0.61^{* *}$ & \\
PPT1 & & $0.61^{* *}$ \\
PPT2 & & 0.47 \\
PPT3 & & -0.03 \\
PPT4 & & 0.21 \\
\hline${ }^{*} p<0.05,{ }^{* *} p<0.01$ & &
\end{tabular}

Table 6: Indicators' weights in formative constructs (Germany)

Following the same process, we also examined the data from China (Table 7, Table 8 and Table 9) and U.S. (Table 10, Table 11 and Table 12), and the results show that reflective measures have good psychometric properties. VIF and tolerance value were also examined for each data set and no indicators have a tolerance value below 0.20 or a VIF value above 5 . On the other hand, most of indicators' weights are not significant, indicating that the results of threat constructs should be interpreted cautiously. 


\begin{tabular}{cccccc}
\hline Scale Item & Item Mean & Item S. D. & $\begin{array}{c}\text { Item } \\
\text { Loading }\end{array}$ & AVE & CR \\
\hline BI1 & 1.97 & 0.64 & 0.78 & 0.60 & 0.82 \\
BI2 & 1.93 & 0.57 & 0.75 & & \\
BI3 & 1.97 & 0.70 & 0.80 & & 0.81 \\
EE1 & 2.86 & 0.95 & 0.67 & 0.59 & \\
EE2 & 2.71 & 1.04 & 0.95 & & \\
EE3 & 3.13 & 1.00 & 0.64 & 0.57 & \\
PE1 & 1.98 & 0.75 & 0.73 & & \\
PE2 & 2.20 & 0.79 & 0.74 & & \\
PE3 & 2.36 & 0.92 & 0.75 & & \\
PE4 & 2.14 & 0.79 & 0.80 & 0.84 \\
SI1 & 2.44 & 0.81 & 0.71 & 0.57 & \\
SI2 & 2.46 & 0.78 & 0.79 & & \\
SI3 & 2.61 & 0.81 & 0.72 & & \\
SI4 & 2.41 & 0.83 & 0.78 & & \\
\hline
\end{tabular}

Table 7: Descriptive statistics, item loadings and constructs' AVE and CR (China)

\begin{tabular}{ccccc}
\hline Construct & BI & EE & PE & SI \\
\hline BI & $\mathbf{0 . 7 8}$ & & & \\
EE & -0.12 & $\mathbf{0 . 7 7}$ & & \\
PE & 0.49 & 0.11 & $\mathbf{0 . 7 5}$ & \\
SI & 0.36 & -0.22 & 0.28 & $\mathbf{0 . 7 5}$ \\
\hline
\end{tabular}

Table 8: Correlation between constructs and square-root of AVEs (China)

\begin{tabular}{ccc}
\hline Construct & PBT & PPT \\
\hline PBT1 & 1.23 & \\
PBT2 & -0.88 & \\
PBT3 & -0.04 & \\
PBT4 & 0.10 & \\
PPT1 & & 1.22 \\
PPT2 & & -0.54 \\
PPT3 & & -0.09 \\
PPT4 & & 0.12 \\
\hline${ }^{*} p<0.05$ & &
\end{tabular}

Table 9: Indicators' weights in formative constructs (China)

\begin{tabular}{cccccc}
\hline Scale Item & Item Mean & Item S. D. & $\begin{array}{c}\text { Item } \\
\text { Loading }\end{array}$ & AVE & CR \\
\hline BI1 & 2.31 & 1.05 & 0.95 & 0.90 & 0.97 \\
BI2 & 2.17 & 1.00 & 0.94 & & \\
BI3 & 2.34 & 1.01 & 0.96 & 0.72 & 0.89 \\
EE1 & 2.31 & 0.85 & 0.81 & & \\
EE2 & 1.93 & 0.89 & 0.89 & 0.82 & 0.95 \\
EE3 & 2.15 & 0.93 & 0.85 & & \\
PE1 & 2.41 & 1.09 & 0.93 & & \\
PE2 & 1.97 & 1.00 & 0.86 & & \\
PE3 & 2.64 & 1.16 & 0.89 & & \\
PE4 & 2.50 & 1.21 & 0.93 & 0.73 & \\
SI1 & 2.98 & 1.08 & 0.90 & & \\
SI2 & 2.88 & 1.03 & 0.93 & & \\
SI3 & 2.94 & 1.05 & 0.81 & & \\
SI4 & 2.98 & 1.00 & 0.77 & & \\
\hline
\end{tabular}

Table 10: Descriptive statistics, item loadings and constructs' AVE and CR (U.S.) 


\begin{tabular}{ccccc}
\hline Construct & BI & EE & PE & SI \\
\hline BI & $\mathbf{0 . 9 5}$ & & & \\
EE & 0.40 & $\mathbf{0 . 8 5}$ & & \\
PE & 0.62 & 0.32 & $\mathbf{0 . 9 0}$ & \\
SI & 0.42 & 0.05 & 0.28 & $\mathbf{0 . 8 5}$ \\
\hline
\end{tabular}

Table 11: Correlation between constructs and square-root of AVEs (U.S.)

\begin{tabular}{ccc}
\hline Construct & PBT & PPT \\
\hline PBT1 & $0.550^{*}$ & \\
PBT2 & 0.128 & \\
PBT3 & 0.346 & \\
PBT4 & 0.152 & \\
PPT1 & & 0.607 \\
PPT2 & & 0.191 \\
PPT3 & & 0.340 \\
PPT4 & & 0.145 \\
\hline${ }^{*} p<0.05$ & &
\end{tabular}

Table 12: Indicators' weights in formative constructs (U.S.)

\subsection{Structural Model Assessment}

PLS examines the structural model with path coefficients and R2 measures (Gefen et al. 2000). Furthermore, the effect size of each path was evaluated by means of Cohen's $f^{2}$ (Cohen 1988). The effect size measures whether an independent variable has a substantial impact on a dependent variable. Figure 2 and Table 13 summarize the results of the structural model assessment for each dataset.

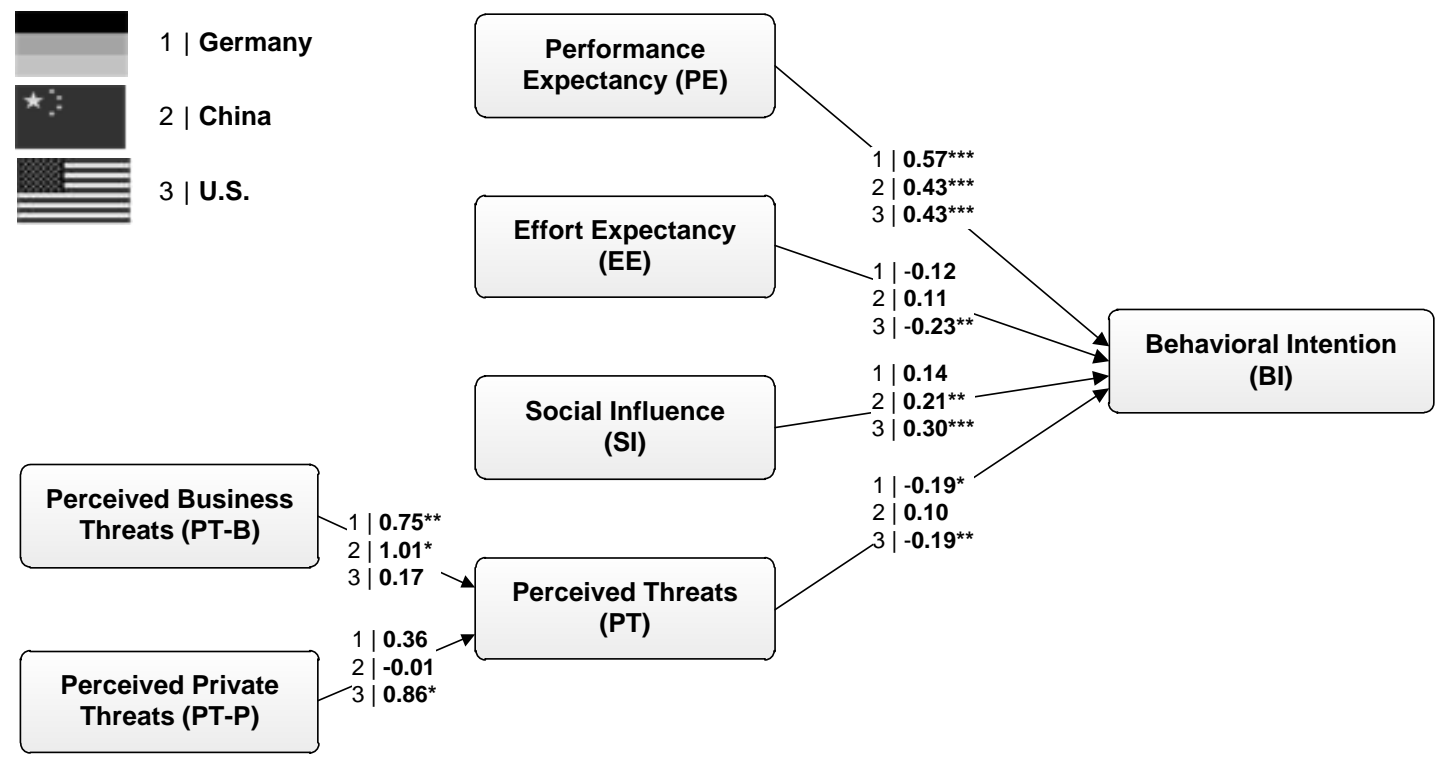

Figure 2: Model of results for Germany $(n=84)$, China $(n=101)$ and the U.S. $(n=117)$ 


\begin{tabular}{lllllll}
\hline Hypothesis & \multicolumn{2}{c}{ Germany $(\mathbf{n}=\mathbf{8 4})$} & \multicolumn{2}{c}{ China $(\mathbf{n}=\mathbf{1 0 1})$} & \multicolumn{2}{c}{ U.S. (n=117) } \\
& \multicolumn{1}{c}{$\boldsymbol{\beta}$} & \multicolumn{1}{c}{$\boldsymbol{f}^{\mathbf{2}}$} & \multicolumn{1}{c}{$\boldsymbol{\beta}$} & \multicolumn{1}{c}{$\boldsymbol{f}^{\mathbf{2}}$} & \multicolumn{1}{c}{$\boldsymbol{\beta}$} & \multicolumn{1}{c}{$\boldsymbol{f}^{\mathbf{2}}$} \\
\hline H1 (PE $\rightarrow$ BI) & $0.57^{* * *}$ & $0.56($ large) & $0.43^{* * *}$ & $0.24($ med.) & $0.43^{* * *}$ & 0.30 (med.) \\
H2 (EE $\rightarrow$ BI) & -0.12 & - & 0.11 & - & $-0.23^{* *}$ & 0.10 (weak) \\
H3 (SI $\rightarrow$ BI) & 0.14 & - & $0.21^{* *}$ & 0.06 (weak) & $0.30^{* * *}$ & 0.17 (med.) \\
H4 (PT $\rightarrow$ BI) & $-0.19^{*}$ & $0.07($ weak) & 0.10 & - & $-0.19^{* *}$ & 0.08 (weak) \\
\hline${ }^{*} p<0.05,{ }^{* *} p<0.01,{ }^{* * *} p<0.001$ & & & &
\end{tabular}

Table 13: Path coefficients and effect sizes

To rule out rival explanations, we added age and gender as controls since those two variables have been identified as important variables in the context of technology adoption (Venkatesh et al. 2003). Both variables were only found to reveal a significant impact on behavioural intention in the American dataset. The effect of both controls was minor, although significant, and there are no qualitative differences after adding age and gender.

Finally, cross-culture comparisons were conducted to test each hypothesis. Specifically, the formula of Keil et al. (2000) is used to assess the statistical differences of the path coefficients between countries:

$$
\mathrm{t}=\frac{\text { Path coefficient }_{\text {Group } 1}-\text { Path coefficent }_{\text {Group2 }}}{\left.\sqrt{\frac{(m-1)^{2}}{(m+n-2)} \times \mathrm{SE}_{\text {Group } 1}^{2}+\frac{(\mathrm{n}-1)^{2}}{(\mathrm{~m}+\mathrm{n}-2)} \times \mathrm{SE}_{\text {Group2 }}^{2}}\right] \times\left[\sqrt{\frac{1}{\mathrm{~m}}+\frac{1}{\mathrm{n}}}\right]}
$$

where $m$ is the sample size for group 1 , and $n$ is the same size for group 2 . These findings are summarized in Table 14 and discussed in the respective section below.

\begin{tabular}{|c|c|c|c|c|c|}
\hline \multirow[b]{2}{*}{ Hypothesis } & \multicolumn{3}{|c|}{ Difference } & \multirow[b]{2}{*}{ Summary } & \multirow{2}{*}{$\begin{array}{l}\text { Hypothesis } \\
\text { Supported? }\end{array}$} \\
\hline & U.S-Germany & $\begin{array}{l}\text { Germany- } \\
\text { China }\end{array}$ & U.S.-China & & \\
\hline$\underset{(\mathbf{P E} \rightarrow \mathrm{HI})}{\mathrm{H1}}$ & $-0.15(-12.90)^{*}$ & $\begin{array}{c}0.14 \\
(11.77)^{*}\end{array}$ & $\begin{array}{c}-0.01 \\
(-0.69)\end{array}$ & $\begin{array}{l}\text { Strongest for } \\
\text { Germans } \\
\text { Strongest for }\end{array}$ & Partially \\
\hline$\underset{(\mathrm{EE} \rightarrow \mathrm{BI})}{\mathrm{H2}}$ & $-0.11(-9.16)^{*}$ & $\begin{array}{c}-0.24 \\
(-15.52)^{*}\end{array}$ & $\begin{array}{c}-0.34 \\
(-23.92)^{*}\end{array}$ & $\begin{array}{l}\text { Americans } \\
\text { and weakest } \\
\text { for Chinese }\end{array}$ & Yes \\
\hline $\begin{array}{c}\text { H3 } \\
(\mathbf{S I} \rightarrow \mathrm{BI})\end{array}$ & $0.16(-14.70)^{*}$ & $\begin{array}{l}-0.07 \\
(5.77)^{*}\end{array}$ & $\begin{array}{c}0.086 \\
(-8.49)^{*}\end{array}$ & $\begin{array}{l}\text { Strongest for } \\
\text { Americans } \\
\text { and weakest } \\
\text { for Germans }\end{array}$ & No \\
\hline $\begin{array}{c}\mathrm{H}_{4} \\
(\mathrm{PT} \rightarrow \mathrm{BI})\end{array}$ & $-0.01(0.42)$ & $\begin{array}{c}-0.28 \\
(-12.57)^{*}\end{array}$ & $\begin{array}{c}-0.29 \\
(-15.26)^{*}\end{array}$ & $\begin{array}{l}\text { Strongest for } \\
\text { Germans and } \\
\text { Americans }\end{array}$ & Partially \\
\hline
\end{tabular}

Each cell shows the difference of path coefficients and corresponding t value.

${ }^{*} p<0.05$

Table 14: Overview of Results

\section{Discussion}

\subsection{Factors driving BYOD adoption and the Impact of Cultural Background}

The results of this empirical study show that future employees' behavioural intention to participate in a corporate BYOD program is indeed a function of their perception of whether: 1) using personal devices at work will improve his or her job performance (performance expectancy); 2) usage is free of effort (effort expectancy); 3) it enhances one's social standing (social influence); and 4) usage is associated with business and private threats (perceived threats). 
It is also shown, that cultural background has a strong impact on the factors motivating certain behavioural intentions. Depending on the cultural setting the assessment of the benefits and risks associated with BYOD differs significantly between participants from different cultural backgrounds.

Performance expectancy is the strongest predictor of behavioural intention independently of the country of origin. Furthermore, it is the only variable with a highly significant effect on behavioural intention across all datasets. The relevance of performance expectations is consistent with prior UTAUT studies (Venkatesh et al. 2003). Analysing the means of the measurement furthermore reveals that future employees in particular expect substantial improvements regarding their mobility on the job.

However, the relationship between performance expectancy and behavioural intention is stronger for Germans but weaker for Americans and Chinese (no significant difference between China and the U.S), which is not fully consistent with H1. This may be explained by the participants chosen for this study. As students -and specifically digital natives- are assumed to be more focussed on their own results it may well be that they transport these expectations towards their own performance into the expected job. As such, the generic view of Hofstede may not hold true for the generation of digital natives. This finding is consistent with Venkatesh and Zhang (2010)'s argument that young people in U.S. and China tend to both emphasize on performance expectancy.

The effect of effort expectancy on behavioural intention is only significant for the U.S. dataset. Results here is consistent with H2: Americans tend to achieve their goals more efficiently than Chinese.

Our findings regarding the effect of social influence are rather mixed. Venkatesh et al. (2003) argue that social influence may not significantly influence intention in voluntary contexts. However, our analysis reveals that social influence imposes the second strongest impact on behavioural intention, and indeed impacts behavioural intention to enrol in a BYOD program in certain cultures. Specifically, the effect of social influence is strongest for Americans and weakest for Germans (non-significant), which does not support H3. One possible explanation is that the perceptions of who is important vary across different cultural contexts. For example, it is possible that for a culture with a high level of power distance (e.g., China), influence from managers is much stronger than that from colleagues. Further research can build upon the findings of Eckhardt et al. (2009) in order to assess whether the social influence of the various referent groups in private or workplace contexts differ within and across different cultures (e.g. the influence of a supervisor in contrast to the influence of colleagues and friends).

The effect of perceived threats is significant for American and Germany students (nonsignificant difference) but not for Chinese students, which partially support H4. Here Chinese students do not perceive threats associated with BYOD to be an issue. Those results are consistent with Weber and Hsee (1998), who show that comparing to Germany and the U.S., Chinese are closest to risk neutrality and that they exhibit the smallest degree of perceived risk aversion. Hence, it is not surprising that their perceptions on potential threats associated with BYOD do not significantly impact their behavioural intention. On the other hand, the risk perceptions of Germans and Americans are comparable.

Regarding the components of perceived threats, perceived business threats appear to have a stronger effect than threats related to private life. In particular, the risk of being responsible for data theft and the risk of violating corporate policies are the strongest indicators, whereas the risk of corrupting the corporate network and service failures are weaker. As indicators of formative constructs are defining characteristics of the construct, the weights indicate an indicator's contribution to the formative construct. As such, the results indicate that future employees are particularly concerned about losing business data and violating policies. Perceived private threats are not significant (except for American students), and analysing indicator weights shows that increasing workload is not perceived as a potential threat. This finding provides evidence that students are already used to blurred boundaries between work 
and leisure-times. Future studies can further examine how people from various cultures perceive different aspects of threats (business vs. private threats).

\subsection{Implications for Practice}

This study revealed several implications for practice, especially to firms which operate in multiple countries. First, the intention to enrol in a BYOD program is significantly related to performance expectancy in every cultural context analysed in this research. Therefore, when offering BYOD programs, companies need to make sure that BYOD can support employees' work and increase their performance. Otherwise, employees may find that using personal devices cannot provide them enough benefits and may decide not to enrol in BYOD programs, even if companies provide them such an option. Even more, such an experience can lead to frustration and eventually to a negative image of the IT-department. This means that IT departments not only need to simply offer a BYOD program, it must be meaningful (i.e. the employees must be able to get real work done using their private devices). This should not end with accessing emails on the private devices but needs to include a broader spectrum of daily work.

Second, although this study shows that effort expectancy, social influence, and perceived threats significantly influence people's intention participate in corporate BYOD programs, the results are mixed and context-dependent. Therefore, companies need to be sensitive to the specific context in which they operate, focus on the corresponding factors and consider differentiating global BYOD initiatives by country. Separate analysis shows that students from the U.S. are particularly concerned with effort expectancy. Therefore, when companies with a significant American workforce design corporate BYOD programs, they need to take into account that participating in BYOD programs have to require little effort (e.g. to set up the devices for business-related task or to ensure that policies are not violated).

Third, social influence significantly impacts people's intention to participate in BYOD programs in China and U.S., but not Germany. Therefore, when companies with workforce from China and U.S. offer corporate BYOD programs, they may let managers promote the services and provide enough support, so that employees who enrol in BYOD programs can improve their better image and reputation within the company.

Finally, participants from Germany and U.S. feel concerned with perceived threats. Therefore, companies with employees from these countries specifically need to reduce people's concerns about potential threats from BYOD. Further, German companies need to pay special attention to potential business-related threats, while American companies need to focus more on factors putting private-life on risk.

\subsection{Limitations and Opportunities for Further Research}

This study focuses on students in their designation as future employees. Although only students with at least three months of relevant work experience were selected, they still have limited work experience and experiences dealing with corporate IT devices. For instance, a comparative study among entrants and more experienced employees could enlarge the knowledge in this field. Also, by only focusing on students with work experiences, our study may have a bias and the results may not hold for all "future employees". Also, only students from certain fields of study have been selected. Results may differ if students from a more diverse setting were included.

Second, only three universities from three countries respectively were selected to recruit participants, so the sample may not represent the whole population of future employees from these three countries. Also, the results may not be able to generalize to other countries/cultural contexts. Besides, measurement reflecting cultural values beyond the countries of origin was not collected. Therefore, the dataset only allowed country-specific analyses of Germany, China and the U.S.

Our theoretical model and proposed hypotheses mainly focus on two cultural dimensions proposed by Hofstede (2001) (i.e., Individualism / collectivism and uncertainty avoidance) 
because these two dimensions are quite relevant to understand BYOD adoption. We do not mean that other dimensions cannot influence BYOD adoption. For example, Srite and Karahanna (2006) find that masculinity/femininity has a moderation effect on the relationship between effect expectancy and behavioural intention. Therefore, masculinity/femininity could be another useful cultural dimension to understand BYOD adoption.

Further research should deepen the examination of cross-cultural differences and integrate espoused cultural variables as moderators of individuals' beliefs on participating in BYOD programs. Following the suggestions of Srite and Karahanna (2006), incorporating espoused national cultural values of masculinity / femininity, individualism / collectivism, power distance, and uncertainty avoidance as moderators seems to be a promising approach for further research.

Notwithstanding these limitations, the findings of this study open up the field for further research. Further research should concentrate on corresponding theoretical approaches and incorporate additional constructs which can be important for an individual's decision whether to participate in BYOD programs. Besides, there can be other negative aspects of IT consumerization behaviour, and future studies can borrow theories from other disciplines to further examine the effect of negative factors on BYOD adoption.

\section{Conclusion}

This study examined cross-national differences of the perceived drivers of IT consumerization on an individual level exemplified by corporate BYOD programs. The study tested the model developed by Weeger et al. (2015) with participants from Germany, China, and U.S. The results indicate that there are significant cross-cultural differences that impact relevance and strength of the impact of the constructs proposed to influence an individual's decision to enrol in a corporate BYOD program. Only individual's expectations regarding gains in job performance, such as increased effectiveness, mobility and productivity was found to impact behavioural intention regardless of an individual's national culture. In contrast, the impact of effort expectancy, social influence, and perceived threats is highly context-dependent. Furthermore, perceptions regarding work-related threats were only found to be significant in Germany and China, whereby perceived threats related to private life seem to be relevant for future employees in the U.S. only. Knowledge acquired from this study is particularly beneficial to multinational firms planning to set up or adjust global BYOD initiatives. The results documented in this paper provide a basis for future research on the antecedents and consequences of IT consumerization in a global context.

\section{References}

Alaskar, M., and Shen, K. N. (2016). Understanding Bring Your Own Device (BYOD) and Employee Information Security Behaviors from A Work-Life Domain Perspective. Proceedings of 22nd Americas Conference on Information Systems.

Amberg, M., M. Hirschmeier, and J.Wehrmann. 2004. "The Compass Acceptance Model for the analysis and evaluation of mobile services."International Journal of Mobile Communications2 (3): 248-259.

Arruda-Filho, E. J. M., J. A. Cabusas, and N. Dholakia. 2010."Social behavior and brand devotion among iPhone innovators."International Journal of Information Management 30 (6): 475-480.

Barclay, D., C. Higgins, and R. Thompson. 1995."The partial least squares (PLS) approach to causal modeling: personal computer adoption and use as an illustration."Technology studies 2 (2): 285-309.

Baskerville, R. 2011. "Individual Information Systems as a Research Arena." European Journal of Information Systems 20 (3): 251-254. 
Bauer, R. A. 1967. "Consumer Behavior as Risk Taking." In Risk Taking and Information Handling in Consumer Behavior, edited by D.F. Cox, 23-33, Cambridge, USA: Harvard University Press.

Beimborn, D., and M. Palitza 2013."Enterprise App Stores for Mobile Applications Development of a Benefits Framework." Paper prested in Nineteenth Americas Conference on Information Systems, Chicago.

Cenfetelli, R. 2004."Inhibitors and Enablers as Dual Factor Concepts in Technology Usage." Journal of the Association for Information Systems5 (11): 472-492.

Chen, C.-D., Y.-W. Fan, and C.-K. Farn 2007. "Predicting electronic toll collection service adoption: An integration of the technology acceptance model and the theory of planned behavior." Transportation Research Part C: Emerging Technologies15 (5): 300-311.

Chin, W. W. 1998. "Commentary: Issues and opinion on structural equation modeling."MIS Quarterly 22 (1): vii-xvi.

Cohen, J. 1988. Statistical Power Analysis for the Behavioral Sciences.Hillsdale, NJ: Routledge Academic.

Colbert, A., Yee, N. and George, G. 2016. "The Digital Workforce and the Workplace of the Future." Academy of Management Journal 59 (3): 731-739

Crossler, R. E., J. H. Long, T. M. Loraas, and B. S. Trinkle. 2014. "Understanding Compliance with Bring Your Own Device Policies Utilizing Protection Motivation Theory: Bridging the Intention-Behavior Gap.” Journal of Information Systems 28(1): 209-226.

Dagwell, R., R. Weber, and R. Kling. 1983. "System Designer's User Models: A Comparative Study and Methodological Critique."Communications of the ACM 26 (11): 987-997.

Davis, F. D. 1989."Perceived Usefulness, Perceived Ease of Use, and User Acceptance of Information Technology." MIS Quarterly 13 (3): 319-340.

Dernbecher, S., R. Beck, and S. Weber. 2013."Switch to Your Own to Work with the Known: An Empirical Study on Consumerization of IT." Paper presented in Nineteenth Americas Conference on Information Systems, Chicago.

Eckhardt, A., S. Laumer, and T. Weitzel. 2009. "Who influences whom? Analyzing workplace referents' social influence on IT adoption and non-adoption." Journal of Information Technology 24 (1): 11-24.

Fenn, J., and H. LeHong. 2011. Hype Cycle for Emerging Technologies. Gartner.

French, A. M., and Guo, C., and Shim, J. P. 2014. Current Status, Issues, and Future of Bring Your Own Device (BYOD) Communications of the Association for Information Systems 35: 191-197.

Gajar, P. K., A. Ghosh, and S. Rai. 2013. "Bring Your Own Device (BYOD): Security Risks and Mitigating Strategies.” Journal of Global Research in Computer Science 4(4): 62-70.

Gefen, D., E. E. Rigdon, and D. Straub. 2011. An Update and Extension to SEM Guidelines for Administrative and Social Science Research. MIS Quarterly, 35 (2): iii-xiv.

Gefen, D., and D. Straub. 2005.“A Practical Guide To Factorial Validity Using PLS-Graph: Tutorial And Annotated Example."Communications of the Association for Information Systems 16:Article 5.

Gefen, D., D. Straub, and M.-C. Boudreau. 2000."Structural equation modeling and regression: guidelines for research practice."Communications of the Association for Information Systems 16 (5): 91-109.

Global mobile statistics. 2013."Global mobile statistics 2013 Part A: Mobile subscribers; handset market share; mobile operators."http://mobithinking.com/mobile-marketingtools/latest-mobile-stats/a\#topsmartphonecountries. Accessed on March $6^{\text {th }}, 2014$. 
Györy, A., A. Cleven, U. Falk, and W. Brenner. 2012. "Exploring the Shadows: IT Governance Approaches to User-Driven Innovation” Paper presented in ECIS Proceedings 2012.

Hair, J. F., G. T. M. Hult, C. M. Ringle, and M. Sarstedt 2014. A Primer on Partial Least Squares Structural Equation Modeling (PLS-SEM). Thousand Oaks, CA: Sage.

Harris, C. 2012."Mobile Consumerization Trends \& Perceptions - IT Executive and CEO Survey," Decisive Analytics, LLC.

Harris, J., B. Ives, and I. Junglas. 2012."IT Consumerization: When Gadgets Turn into Enterprise IT Tools."MIS Quarterly Executive 11 (3): 99-112.

Harris, J. G., and I. Junglas. 2011.“The Genie Is Out of the Bottle: Managing the Infiltration of Consumer IT Into the Workforce,” Accenture Institute for High Performance.

Harris, M. A., K. Patten, and E. Regan. 2013."The Need for BYOD Mobile Device Security Awareness and Training" Paper presented in Nineteenth Americas Conference on Information Systems, Chicago.

Harris, M., K. Patten, E. Regan, and J. Fjermestad. 2012. "Mobile and Connected Device Security Considerations: A Dilemma for Small and Medium Enterprise Business Mobility." Paper presented in Eighteenth Americas Conference on Information Systems, Seatle, Washington.

Hofstede, G. 2001. Culture's Consequences: comparing values, behaviors, instituions, and organization across nations. Beverly Hills, CA: Sage.

Hofstede, G. 2013. "What about Germany." Retrieved 04.07.2013, from http://geerthofstede.com.

Holtsnider, B., and B. D. Jaffe. 2012. IT Manager's Handbook: Getting Your New Job Done, Waltham, MA: Morgan Kaufmann.

Hovav, A., and Putri, F. F. (2016). This is my device! Why should I follow your rules? Employees' compliance with BYOD security policy. Pervasive and Mobile Computing. In Press

Hulland, J. 1999. "Use of Partial Least Squares (PLS) in Strategic Management Research: A Review of Four Recent Studies." Strategic Management Journal 20 (2): 195-204.

Hung, S.-Y., and C.-M.Chang. 2005.“User Acceptance of WAP Services: Test of Competing Theories.” Computer Standards \& Interfaces 27 (4): 359-370.

Ingalsbe, J. A., D. Shoemaker, and N. R. Mead. 2011.“Threat Modeling the Cloud Computing, Mobile Device Toting, Consumerized Enterprise - an overview of considerations" Paper presented in Seventeenth Americas Conference on Information Systems, Detroit.

Jaramillo, D., N. Katz, B. Bodin, W. Tworek, R. Smart, and T. Cook 2013. Cooperative solutions for Bring Your Own Device (BYOD). IBM Journal of Research and Development 57(6):5:1-5:11.

Johnson, N., and K. Joshi. 2012."The Pathway to Enterprise Mobile Readiness: Analysis of Perceptions, Pressures, Preparedness, and Progression.” Proceedings of Eighteenth Americas Conference on Information Systems, Seattle, Washington.

Keil, M., B. C. Y. Tan, K. Wei, T. Saarinen, V. Tuunainen, and A. Wassenaar. 200o. "A CrossCultural Study on Escalation of Commitment Behavior in Software Projects," MIS Quarterly, 24 (2), 299-324.

Lebek, B., K. Degirmenci, and M. H. Breitner. 2013."Investigating the Influence of Security, Privacy, and Legal Concerns on Employees' Intention to Use BYOD Mobile Devices." Paper presented in Nineteenth Americas Conference on Information Systems, Chicago. 
Lee, K., K. Joshi, and M. Bae. 2009. "A Cross-National Comparison of the Determinants of Customer Satisfaction with Online Stores."Journal of Global Information Technology Management 12 (4): 25-51.

Li, D., Chau, P. Y. K., and Slyke, C. V. (2010). A comparative Study of Individual Acceptance of Instant Messaging in the US and China: A Structural Equation Modeling Approach. Communications of the Association for Information Systems (26): 85-106.

Leidner, D. E., and T. Kayworth. 2006."Review: a review of culture in information systems research: toward a theory of information technology culture conflict."MIS Quarterly 30 (2): 357-399.

Lindell, M. K., and D. J. Whitney. 2001."Accounting for common method variance in crosssectional research designs.”Journal of applied psychology 86 (1): 114-121.

Lohmöller, J.-B. 1989.Latent variable path modeling with partial least squares, PhysicaVerlag Heidelberg.

Lomas, N. 2014. "Gartner: Smartphone Sales Finally Beat Out Dumb Phone Sales Globally In 2013, With 968M Units Sold.” http://techcrunch.com/2014/02/13/smartphonesoutsell-dumb-phones-globally/. Feb. 13th, 2014. Accessed on March 6th, 2014.

López-Nicolás, C., F. J. Molina-Castillo, and H. Bouwman. 2008.“An assessment of advanced mobile services acceptance: Contributions from TAM and diffusion theory models."Information \& Management 45 (6): 359-364.

Mallat, N., M. Rossi, V. K. Tuunainen, and A. Öörni. 2008."An empirical investigation of mobile ticketing service adoption in public transportation."Personal and Ubiquitous Computing 12 (1): 57-65.

McCoy, S., D. F. Galletta, and W. R. King. 2005. "Integrating National Cultre into IS Research: The need for Current Individual-Level Measures."Communications of the Association for Information Systems 15: 211-224.

Min, S.-J. 2010. "From the Digital Divide to the Democratic Divide: Internet Skills, Political Interest, and the Second-Level Digital Divide in Political Internet Use." Journal of Information Technology \& Politics (7:1): 22-35

Moore, G. C., and I. Benbasat. 1991."Development of an Instrument to Measure the Perceptions of Adopting an Information Technology Innovation."Information Systems Research 2 (3): 192-222.

Murdoch, R., J. G. Harris, and G. Dvore. 2010. "Can Enterprise IT Survive the Meteor of Consumer Technology?” Accenture Institute for High Performance.

Niehaves, B., S. Köffer, and K. Ortbach. 2012."IT Consumerization - A Theory and Practice Review." Paper presented in Eighteenth Americas Conference on Information Systems, Seatle, Washington.

Niehaves, B., S. Köffer, and K. Ortbach. 2013."The Effect of Private IT Use on Work Performance - Towards an IT Consumerization Theory." Paper presented in International Conference on Wirtschaftsinformatik, Leipzig.

Pagani, M. 2004. "Determinants of adoption of third generation mobile multimedia services." Journal of Interactive Marketing 18 (3): 46-59.

Park, J., D. Lee, and J. Ahn.2004."Risk-Focused E-Commerce Adoption Model: A Cross Country Study."Journal of Global Information Technology Management 7 (2): 6-30.

Podsakoff, P. M., S. B. MacKenzie, J.-Y. Lee, and N. P. Podsakoff. 2003.“Common Method Biases in Behavioral Research: A Critical Review of The Literature and Recommended Remedies."Journal of applied psychology 88 (5): 879-903.

Prensky, M. 2001.“Digital Natives, Digital Immigrants.”On the Horizon 9 (5): 1-6. 
Ragu-Nathan, T. S., M. Tarafdar, B. S. Ragu-Nathan, and Q. Tu. 2008. "The Consequences of Technostress for End Users in Organizations: Conceptual Development and Empirical Validation," Information Systems Research 19 (4): 417-433.

Ringle, C.M., S. Wende, and S. Will. 2005. SmartPLS 2.o (M3) Beta. Hamburg, http://www.smartpls.de.

Romer, H. 2014. Best practices for BYOD security. Computer Fraud \& Security, 2014(1): 1315 .

Schmidt, M. B., A. C. Johnston, K. P. Arnett, J. Q. Chen, and S. Li. 2008. "A Cross-Cultural Comparison of U.S. and Chinese Computer Security Awareness.” Journal of Global Information Management 16 (2): 1-103.

Srite, M., and E. Karahanna. 2006. "The Role of Espoused National Cultural Values in Technology Acceptance."MIS Quarterly 30 (3): 679-704.

Tarafdar, M., Q. Tu, B. S. Ragu-Nathan, and T. S. Ragu-Nathan. 2007. "The impact of technostress on role stress and productivity," Journal of Management Information Systems 24 (1): 301-328.

Tarique, I., and R. S. Schuler. 2010."Global talent management: Literature review, integrative framework, and suggestions for further research.” Journal of World Business 45 (2): $122-$ 133 .

Thompson, R. L., C. A. Higgins, and J. M. Howell. 1991."Personal Computing: Toward a Conceptual Model of Utilization."MIS Quarterly 15 (1): 125-143.

Tokuyoshi, B. 2013. The security implications of BYOD. Network Security 2013 (4): 12-13.

Triandis, H. C. 1989."The Self and Social Behavior in Differing Cultural Contexts." Psychological Review 96 (3): 506-520.

Triandis, H. C., R. Bontempo, M. J. Villareal, M. Asai, and N. Lucca.1988.“Individualism and Colectivism: Cross-cultural perspectives and Self in Group Relationshps."Journal of Personality \& Social Psychology 54 (2): 323-338.

Steelman, Z.; Lacity, M. and Sabherwal, R. 2016. "Charting Your Organization's Bring-YourOwn-Device Voyage." MISQ Executive 15 (2): 85-104.

Venkatesh, V., M. Morris, G. Davis, and F. Davis. 2003."User Acceptance of Information Technology: Toward a Unified View."MIS Quarterly 27 (3): 425-478.

Venkatesh, V. and Zhang, X. 2010. "Unified Theory of Acceptance and Use of Technology: U.S. Vs. China," Journal of Global Information Technology Management 13(1): 5-27.

Vogel, R., T. Kocoglu, and T. Berger. 2010. Desktopvirtualisierung: Definitionen Architekturen - Business-Nutzen, Wiesbaden: Vieweg Verlag, Friedr, \& Sohn Verlagsgesellschaft mbH.

Wang, W., and Nemati, H. (2016). Understanding Usage of Bring Your Own Device (BYOD): A Complex Adaptive Systems Perspective. Proceeding of 22nd Americas Conference on Information Systems.

Weber, E. U., and C. Hsee. 1998. "Cross-Cultural Differences in Risk Perception, but CrossCultural Similarities in Attitudes Towards Perceived Risk." Management Science 44 (9): 1205-1217.

Weeger, A., X. Wang, and H. Gewald. 2015. "IT Consumerization: BYOD-Program Acceptance and its Impact on Employer Attractiveness." Journal of Computer Information Systems 56(1): 1-10.

Weiß, F., and J. Leimeister. 2012. "Consumerization - IT Innovations from the Consumer Market as a Challenge for Corporate IT.”Business \& Information Systems Engineering 54 (6): 363-366. 
Zhao, X., B. B. Flynn, and A. V. Roth. 2007. "Decision Sciences Research in China: Current Status, Opportunities, and Propositions for Research in Supply Chain Management, Logistics, and Quality Management," Decision Science 38 (1): 39-80.

Copyright: (C) 2017 Wang, Weeger \& Gewald. This is an open-access article distributed under the terms of the Creative Commons Attribution-NonCommercial 3.0 Australia License, which permits non-commercial use, distribution, and reproduction in any medium, provided the original author and AJIS are credited.

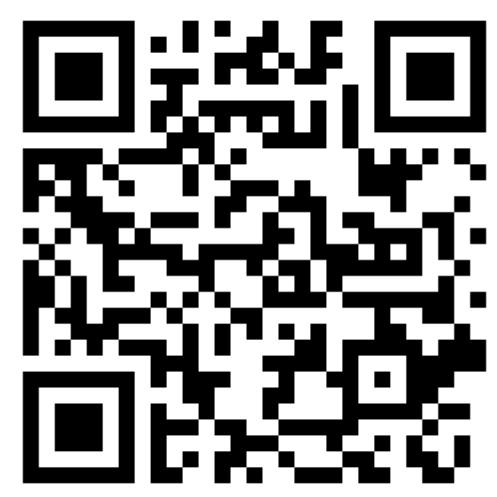




\section{Appendix A: Instruments}

\begin{tabular}{|c|c|c|}
\hline Abbr. & Definition & Source \\
\hline BI1 & If a BYOD program is offered, I intend to use it. & \multirow{3}{*}{$\begin{array}{l}\text { Adapted from } \\
\text { Venkatesh et al. } \\
\text { (2003) }\end{array}$} \\
\hline $\mathrm{BI} 2$ & If a BYOD program is offered, I predict I would use it. & \\
\hline $\mathrm{BI} 3$ & If a BYOD program is offered, I plan to use it. & \\
\hline PE1 & $\begin{array}{l}\text { Participating in the program would increase my effectiveness } \\
\text { on the job. }\end{array}$ & Davis (1989) \\
\hline PE2 & $\begin{array}{l}\text { Participating in the program would increase my mobility on } \\
\text { the job. }\end{array}$ & Self-designed \\
\hline $\mathrm{PE}_{3}$ & $\begin{array}{l}\text { Participating in the program would increase my job } \\
\text { motivation. }\end{array}$ & \multirow{2}{*}{$\begin{array}{l}\text { Adapted from } \\
\text { Venkatesh et al. } \\
(2003)\end{array}$} \\
\hline $\mathrm{PE} 4$ & $\begin{array}{l}\text { Participating in the program would increase my productivity } \\
\text { on the job }\end{array}$ & \\
\hline EE1 & $\begin{array}{l}\text { Participating in the program would be too complicated; it is } \\
\text { difficult to understand which handling leads to the desired } \\
\text { work support. }\end{array}$ & \multirow{2}{*}{$\begin{array}{l}\text { Adapted from } \\
\text { Thompson et al. (1991) }\end{array}$} \\
\hline EE2 & $\begin{array}{l}\text { It would take too long to learn how to participate in the } \\
\text { program to make it worth the effort. }\end{array}$ & \\
\hline EE3 & $\begin{array}{l}\text { Participating in the program would lead to the situation that I } \\
\text { would often require additional help. }\end{array}$ & Self-designed \\
\hline SI1 & $\begin{array}{l}\text { I predict that people in a company who participate in the } \\
\text { program have more prestige than those who do not. }\end{array}$ & \multirow{3}{*}{$\begin{array}{l}\text { Adapted from Moore } \\
\text { and Benbasat (1991) }\end{array}$} \\
\hline SI2 & $\begin{array}{l}\text { I predict that people in a company who participate in the } \\
\text { program have a high profile. }\end{array}$ & \\
\hline $\mathrm{SI} 3$ & $\begin{array}{l}\text { I predict that participating in the program is a status symbol } \\
\text { for people in a company. }\end{array}$ & \\
\hline SI4 & $\begin{array}{l}\text { I predict that people in my peer group who participate in the } \\
\text { program can thereby improve their image. }\end{array}$ & Self-designed \\
\hline BPT1 & $\begin{array}{l}\text { Participating in a corporate "Bring Your Own Device" program } \\
\text { increase the risk that I lose business data }\end{array}$ & \multirow{8}{*}{$\begin{array}{l}\text { Self-designed based on } \\
\text { Niehaves et al. (2012) }\end{array}$} \\
\hline$\overline{\mathrm{BPT} 2}$ & $\begin{array}{l}\text { Participating in a corporate "Bring Your Own Device" program } \\
\text { increase the risk that I corrupt the corporate network with } \\
\text { malware }\end{array}$ & \\
\hline BPT3 & $\begin{array}{l}\text { Participating in a corporate "Bring Your Own Device" program } \\
\text { increase the risk that I violate company policies }\end{array}$ & \\
\hline BPT4 & $\begin{array}{l}\text { Participating in a corporate "Bring Your Own Device" program } \\
\text { increase the risk that I am not able to work because of a service } \\
\text { failure }\end{array}$ & \\
\hline PPT1 & $\begin{array}{l}\text { Participating in a corporate "Bring Your Own Device" program } \\
\text { increase the risk that I lose private data }\end{array}$ & \\
\hline PPT2 & $\begin{array}{l}\text { Participating in a corporate "Bring Your Own Device" program } \\
\text { increase the risk that too restrictive corporate policies limit the } \\
\text { usage of my private device }\end{array}$ & \\
\hline $\mathrm{PPT}_{3}$ & $\begin{array}{l}\text { Participating in a corporate "Bring Your Own Device" program } \\
\text { increase the risk that private data can be viewed by my } \\
\text { company }\end{array}$ & \\
\hline $\mathrm{PPT}_{4}$ & $\begin{array}{l}\text { Participating in a corporate "Bring Your Own Device" program } \\
\text { increase the risk that increasing workload force me to do } \\
\text { business after hours }\end{array}$ & \\
\hline
\end{tabular}

Table A.1: Measurement instrument (all items were measured on 5-point Likert scales.) 